\title{
Ontological Syncretistic Noneism
}

\author{
Alberto Voltolini \\ Philosophy \\ Università degli Studi di Torino
}

\begin{abstract}
Whether the noneist really can avoid postulating different kinds of being-in particular, whether he can explain to those of us who think that the correct answer to the question 'What exists?' is 'Everything' just how and why our conception of what objects our bound individual variables range over is unduly narrow-is one of the many difcult and delicate questions which I cannot pursue here. (Hale 2007:95fn.2)
\end{abstract}

In this paper I want to claim, first, that despite close similarities, noneism (as developed in both Routley 1980 and Priest 2016) and Crane's (2013) psychological reductionism are different ontological doctrines. For unlike the latter, the former is ontologically committed to objects that are nonentities. Once one splits ontological from existential commitment, this claim, I guess, is rather uncontroversial. Second, however, I want to claim something more controversial; namely, that this ontological interpretation of noneism naturally makes noneism be nonstandardly read as a form of allism, to be however appropriately distinguished from a Quinean form of allism in terms of the different scope of the overall ontological domain on which the only existential quantifier that there is ranges. This may orient a noneist towards a syncretistic view of existence, according to which, appearances notwithstanding, existence as a whole is captured both by means of second-order and by means of first-order related notions.

\section{Noneist ontological commitment to nonexistents}

In (2013), Tim Crane has reprised and developed some theses that he had originally defended in (2001). According to Crane, one can truly speak and think, both singularly 
and generically, of nonexistent intentional objects, even though, unlike existent intentional objects, those items are not entities. However, existence is the main metaphysically unsubstantive difference between entities and such objects. In other words, nonexistent intentionalia do not constitute a sui generis metaphysical kind: they are not exotica, in Sainsbury's (2010) terms. Being nonentities, anyway, they do not figure within the overall ontological array of the world. As a result, pace Quine (1953), true existential quantifications over such objects is not a mark of ontological commitment; nor is such a commitment entailed by true simple sentences about them. ${ }^{1}$ In order to explain how all such sentences concerning nonexistent intentionalia may be true, Crane appeals to a form of psychological reductionism. Such sentences are made true by facts in the world that do not involve such objects; ultimately, psychological facts, such as one's having mental representations involving mental files about such objects.

Certainly, as Crane himself underlines, ${ }^{2}$ there are many similarities between Crane's own perspective and noneism, as developed both in Routley (1980) and in Priest (2016). To begin with, for noneists nonexistent objects in general differ from entities, insofar as unlike the former, the latter exist. One might think that for noneists, the domain of nonexistent objects is broader than the domain of Crane's nonexistent intentionalia. For one thing, this thought is surely true, insofar as noneists include in that domain not only mathematical items and possible but also as impossible worlds, on which Crane is mostly silent. ${ }^{3}$ However, as noneists acknowledge, ${ }^{4}$ just as for Crane the epistemic source of nonexistence in general is intentionality. For nonexistent objects are originally conceived in intentional states that are directed upon them. Moreover, also for noneists nonexistent intentionalia do not constitute a sui generis metaphysical kind. Leaving aside the particular case of mathematical items, metaphysically speaking both a nonexistent object and an existent entity are concreta; their difference as to existence makes no metaphysically relevant difference between them, nor is any metaphysical difference produced by their respective being thought. ${ }^{5}$ Finally, noneists manifestly share Crane's polemical attitude against Quine's criterion of ontological commitment. As both Routley and Priest explicitly underline, to be is not to be the value of a bound variable, but to exist, a first-order property that only entities possess; nonexistent objects do not have any form of existence whatsoever. ${ }^{6}$ Thus, just as for Crane sentences like:

(1) There are / some intentional objects (that) do not exist

(2) Some characters in the Bible (e.g. Abraham and Moses) do not exist

\footnotetext{
${ }^{1}$ Ideas similar to those of Crane have been defended, merely with respect to nonexistent objects of hallucination, originally by Smith (2002). They also occur in Sainsbury (2010, 2017), Sainsbury-Tye (2012). 
are true even if they do not commit us to fictional or anyway nonexistent intentional objects, ${ }^{7}$ for noneists quantified sentences introduced by the unloaded particular quantifier "some(thing)" do not (at least existentially) commit us to anything, unlike sentences introduced by the loaded particular quantifier, the existential quantifier "There is/exists". 8

To be sure, there seems to be a basic difference between noneists and Crane. Noneists unreservedly accept Meinong's (1960) Principle of the Independence of being-so, having properties, from existence. ${ }^{9}$ For Routley, this allows nonexistent objects to have a variety of properties, typically the properties characterizing those objects themselves (constituting their specific nature, as some would say). ${ }^{10}$ Yet since for Crane the majority of properties are existence-entailing, for him the principle holds just in a limited series of cases, typically wrt categorical properties that yield the general metaphysical nature of the nonexistent objects at stake. So for instance, for Crane, unlike Routley, it is not the case that the nonexistent Pegasus has the property of being a winged horse, for this is an existenceentailing property. Yet for him Pegasus has the property of being a mythical object, insofar as this property qualifies the general metaphysical nature it has utterly independently of the fact that it does not exist. ${ }^{11}$ Yet while it is true that this different adhesion to the Principle of Independence marks a difference between Crane's perspective and Routley's perspective on nonexistents, it is more controversial whether Crane and Priest are really different on this respect. This depends on the fact that Priest adheres in a different way from Routley to Routley's himself (actually, Meinong's) ${ }^{12}$ Characterization Postulate, which Crane does not endorse as such. According to this postulate, "objects, whether they exist or not, actually have the properties which are used to characterize them, for example, where $f$ is a characterizing feature, the item which $f$ s indeed $f$ s." (1980:46). In order to avoid wellknown puzzles, Routley endorses this postulate only as far as characterizing properties are concerned. Thus, the golden mountain, which does not exist, has both the characterizing properties of being golden and being mountaneous. Yet the existent golden mountain, which does not exist as well, has the same characterizing properties as the golden mountain, yet it simply fails to have the noncharacterizing property of existence. Therefore pace Russell (1905a,b), it does not violate the law of noncontradiction by existing and failing to exist at one and the same time. ${ }^{13}$ Yet Priest claims that the postulate holds unrestrictedly, by i) dropping the distinction between characterizing and noncharacterizing properties, ii) accepting the idea that many properties are existence-entailing, and yet iii) holding that an object has the properties that characterize it in the worlds that are (partially) described by its relevant representation. Since these worlds may well differ from the actual

\footnotetext{
${ }^{7}$ Cf. Crane $(2011: 5,17)$.

${ }^{8}$ Cf. Routley (1980:9-10,81,424), Priest (2016:13-4,198).

${ }^{9}$ Cf. Routley (1980:24-5), Priest (2016:82,319).

${ }^{10}$ Cf. Routley (1980:45-6).

${ }^{11}$ Cf. Crane (2013:27,59-63).

${ }^{12}$ Cf. Meinong (1960:82).

${ }^{13}$ Cf. Routley (1980:47,90-1).
}

Australasian Journal of Logic (15:2) 2018 Article no. 2.5 
one, the problem Russell raises vanishes. Just as the golden mountain, the existent golden mountain, which actually fails to exist as well, has the existence-entailing properties of being golden and being mountaneous in the worlds in which it also has the property of existence; namely, the worlds that realize the way it is represented to be in its characterization. Since in this case such worlds are evidently not the actual one, no contradiction arises. ${ }^{14}$ Now, this move entails that, although an actually nonexistent object does not actually have the properties $F, G, H \ldots$ by means of which it is characterized if they are existenceentailing properties, it still actually has the properties of being represented as $F$, as $G$, as $H \ldots{ }^{15}$ For instance, albeit nonexistent, both the golden mountain and the existent golden mountain actually have the property of being represented as a golden mountain. Yet Crane admits that nonexistent intentionalia actually and basically have what following McGinn (2002) he calls representation-dependent properties, i.e., properties that depend for their true attribution on the existence of some representations; ultimately, intentional states. ${ }^{16}$ Being represented as being a golden mountain is therefore a property that also for Crane the golden mountain actually possesses, insofar as it is the nonexistent intentionale of an intentional state in which it is so represented. Thus, the explicitly different attitudes towards the Principle of Independence and the Characterization Postulate do not mark a genuine difference between Crane and at least the Priestian version of noneism.

To my mind, the real point of difference is another. As I said before, Crane subscribes to a form of psychological reductionism, according to which sentences about nonexistent intentionalia are made true by facts in the world involving no such objects, ultimately representational facts, for reality as a whole does not contain such objects: "the entire world - reality, being, the universe, call it what you like - does not contain more than what exists" (2013:3). Yet for noneists nonexistent objects, although they do not exist, are part of reality: "the admission of nonesixtent objects is meinongianism, or, as I shall call it [...] noneism" (Priest 2016:14). Thus, nonexistents contribute to constitute the overall ontological domain. As Priest acknowledges, Crane's psychological reductionism is a form of noneist antirealism, to be distinguished from his own (and Routley's) realist noneism. ${ }^{17}$

To be sure, Priest himself suggests that this may be seen just a terminological dispute. ${ }^{18}$ If by "reality" one means the same as "being", as Crane explicitly says in the above

\footnotetext{
${ }^{14}$ Cf. Priest (2016:84-5).

${ }^{15}$ As Priest implicitly admits by ascribing nonexistents intentional properties, like being thought of. Cf. (2016:216).

${ }^{16}$ Cf. Crane (2013:60).

${ }^{17}$ Cf. Priest (2016:275). To be sure, he uses "anti-realism" in a nonstandard way, namely to mean a form of noneism with variable domains that admits nonexistent objects just in the worlds in which they figure by depending on the mental activities of their creators $(i b: 264)$. This way of putting things is often considered to be appealing wrt fictional objects (cf. Berto 2013). Yet ontologically speaking this is standardly taken to be a form of realism (cf. e.g. Thomasson 1999); it may be taken as an antirealism just in a metaphysical sense, insofar as the objects in question are mind-dependent ones. In this sense, Crane is not an antirealist, for he does not allow for nonexistent intentionalia even as mind-dependent items.

${ }^{18}$ Cf. Priest (2016:273fn.22).
}

Australasian Journal of Logic (15:2) 2018 Article no. 2.5 
quotation, then clearly enough nonexistents are not part of reality, since they have no form of being whatsoever. Yet if by "reality" one means something that is beyond being and nonbeing in the sense of Meinong (1960), "as applied to the domain of all objects" (Priest 2016:273fn.22), then clearly enough, nonexistents are part of reality.

Yet to my mind, the dispute is more than terminological. For Crane, intentionalia are objects of thought in the very same way as, in direct object linguistic constructions, grammatical objects are targets of transitive verbs. ${ }^{19}$ This means that by themselves, intentionalia have no ontologically constitutive import whatsoever. Only if they exist, i.e., only if they are entities, they have for Crane such an import; if not, they are simply ways for us to identify certain thoughts as different entities. As he says ${ }^{20}$ a thought of Vulcan is different from a thought of Zeus insofar as they may be respectively identified as a thought about a certain intentionale and as a thought about another intentionale just as, one may add, dancing a tango and dancing a waltz are different dancings insofar as the first is a tango dance (namely, a way of dancing: dancing tangoely, as adverbialists on intentionalia would say) ${ }^{21}$, while the second is a waltz dance (namely, another way of dancing: dancing waltzly, as again adverbialists would say). This is something a noneist is far from accepting, since for her nonexistent intentionalia have such a constitutive import. As Routley says, a thought of a unicorn is different from a thought of a mermaid insofar as they are about nonexistent objects that have a different specific nature. ${ }^{22}$

The issue can be clearly seen if we consider the case of an indeterminate intentional object, what a nonspecific form of thought seemingly mobilizes. For Crane, just as a specific (and singular) ${ }^{23}$ thought by Leverrier about Vulcan has the determinate object Vulcan as its intentionale ${ }^{24}$ a nonspecific thought such as Vladimir's desire of a bottle of inexpensive burgundy has the indeterminate object a bottle of inexpensive burgundy, i.e., some such bottle or other, as its intentionale. ${ }^{25}$ Now if we move from Crane to Sainsbury and Tye, who draw a distinction between things and objects viz. entities structurally analogous to Crane's distinction between (intentional) objects and entities, we have that from their similar sentences reporting intentional objectual states respectively read specifically and nonspecifically (the second one involving a famous example of Quine):

(3) Macbeth hallucinated a dagger

(4) I desire a sloop

\footnotetext{
${ }^{19} \mathrm{Cf}$. Crane (2001:15-7, 2013:91-2). This does not mean that for Crane intentionalia are grammatical objects, but just, as I said in the text, that their relation to thoughts about them is structurally the same as the relation of grammatical objects to the sentences that contain the relevant transitive verbs.

${ }^{20}$ Cf. Crane (2001:25-6).

${ }^{21}$ Cf. e.g. Kriegel (2011).

${ }^{22}$ Cf. Routley (1980:45).

${ }^{23}$ This specification is intended by Crane to account for the difference between specific yet singular thoughts and specific yet plural thoughts, thoughts that are about pluralities. Cf. Crane (2013:141).

${ }^{24}$ Cf. Crane (2013:92).

${ }^{25} i b$.; see also Crane (2001:16).
} 
one can legitimately infer, respectively:

(5) There is something Macbeth hallucinated (namely, a dagger)

(6) There is something I desire (namely, a sloop)

which are true even though they commit us to nothing whatsoever. ${ }^{26}$ So, for a psychological reductionist there is no ontologically relevant difference between a determinate, though nonexistent, intentionale and an indeterminate intentionale, insofar as both are just like grammatical targets. Yet for noneists on the one hand, to infer (5) is legitimate insofar as it quantifies over a nonexistent intentionale, while on the other hand, (6) seems far from being legitimate, for the only legitimate inference a noneist mentions that one can draw from (4) is:

(7) I desire that I have something / there is something (namely, a sloop) I have ${ }^{27}$

where the particular quantifier has an embedded position, so it quantifies over nothing at all. ${ }^{28}$ Now, it is hard not to spell out such a difference in ontological terms. On the one hand, for the noneist the determinate, though nonexistent, intentionale that (3) mobilizes figures within the overall ontological domain. Yet on the other hand, for her the indeterminate intentionale that (4) mobilizes does not figure within that domain. For the noneist, therefore, there is an ontological difference between the two intentionalia that the psychological reductionist cannot account for. The most natural way of accounting for that difference is to say that one is ontologically committed to the first yet not to the second intentionale, even though, since the first does not exist, one is not existentially committed to it. Routley is (sometimes at least) tempted by adopting this way of putting things, even though normally for him ontological commitment and existential commitment collapse on one another. For instance, he once says that if "ontological commitment is determined through preparedness to quantify, [then] noneism is ontologically committed to what it maintains does not exist, e.g. possibilia, abstractions, and so on" (1980:414fn.1). Now, although Priest explicitly says that ontology is just the doctrine of what has being (viz., exists), ${ }^{29}$ it is quite coherent for the noneist to adopt a wider conception of ontology, according to which noneism is the ontological doctrine both of what exists and of what does not exist. Sometimes Meinong as well allowed for this way of putting things, by accepting that "ontology" may be a different label for what he normally calls "Theory of Objects": "'Ontology,' 'the theory of categories,' and the other subjects assigned more or

\footnotetext{
${ }^{26}$ Cf. Sainsbury (2010:317), Sainsbury-Tye (2012:114). For other similar examples see Sainsbury (2017). Curiously enough, Crane (2013:56) does not allow for an inference of that kind from (3) to (5). Yet probably he has there in mind just a loaded reading of the particular quantifier.

${ }^{27}$ In this case, as Hale (2007:100fn.10) underlines, the embedded quantifier is preferably loaded. But in other cases it may be unloaded as well.

${ }^{28}$ Cf. Priest (2016:65-7). To be sure, Sainsbury himself acknowledges that "there is a sloop such that I desire it" is not inferable from (4). Cf. (2010:305,317).

${ }^{29}$ Cf. Priest (2016:250).
} 
less unanimously to metaphysics [the theory of existents] have occasionally allowed a place for interests extending beyond the limits of the real [Wirklichen]" (1960:107).

\section{Noneist allism}

By focusing on the contrast between sentences like (5), admittedly true, and (6), which seems to be false, the previous reflections have shown not only the perhaps obvious result that room has been found for a noneist to be ontologically committed to existents as well as to nonexistents, but also the definitely less obvious result that there is a chance for such a commitment to be expressed à la Quine, i.e., quantificationally. Now, once noneist ontological commitment is captured by true existential quantification, one may reformulate this commitment in the terms put forward by Lewis (1990). Following Lewis, one may indeed say that noneism is a form of allism, namely a doctrine ontologically committed to everything, once one holds that the noneist unloaded particular quantifier and the Quinean quantifier, the existential quantifier, are just one and the same quantifier, i.e., an expression endowed with exactly the same meaning, for one can translate one quantifier by means of the other one - translation has to go both ways, as Priest himself underlines. ${ }^{30}$ Indeed, according to this way of putting things, Routley "quantifies just as we do; over everything" (Lewis 1990:29, my italics).

Notoriously, Priest rejects this interpretation, by favoring Lewis' alternative interpretation of the matter, according to which Routley's loaded particular quantifier is the same as Quine's existential quantifier. ${ }^{31}$ Yet it seems to me that Lewis' original interpretation is, if not correct, at least desirable. For it may convincingly account for how the ontological disagreement between noneists and philosophers who not only stick to the Quinean existential quantifier but also dislike, à la Quine, Meinongian ontological jungles - let me call them the Quine-inspired philosophers - may be a genuine disagreement, not a disagreement in the meaning of the relevant sentences. This would be impossible if the noneist unloaded particular quantifier and the Quinean existential quantifier had different meanings, as per the second interpretation. As Lewis himself remarks, "Disagreement remains. But Routley's heresy becomes more intelligible from the standpoint of orthodoxy and, reciprocally, orthodoxy becomes more intelligible from Routley's standpoint" (ib.). ${ }^{32}$

If the disagreement is genuine and not a disagreement in the meaning of the quantifier

\footnotetext{
${ }^{30}$ Cf. Priest (2016:205).

${ }^{31}$ Cf. Lewis (1990:26), Priest (2016:199).

${ }^{32}$ In following Lewis' interpretation of noneism, I am close to Woodward's (2013) reading of the matter. Yet it seems to me that Woodward goes too far by suggesting that the disagreement between a noneist and a Quine-inspired philosopher is merely verbal, insofar as "there is a systematic and recursively specifiable way to translate between the two theories which has the following result: that for every sentence which $T_{1}$ says is true, there is a corresponding sentence which $\mathrm{T}_{2}$ says is true and for every sentence which $\mathrm{T}_{2}$ says is true, there is a corresponding sentence which $T_{1}$ says is true" (2013:190). As we will immediately see, the disagreement is rather a relativistic disagreement, concerning the truth-value of the relevant sentences.
}

Australasian Journal of Logic (15:2) 2018 Article no. 2.5 
expression, what does it amount to? To my mind, this disagreement concerns the scope of the overall ontological domain, as differently fixed by differently taking the extension of a certain first-order predicate standing for a substantive property of existence, i.e., as an universal vs. a nonuniversal extension respectively, while identically taking the extension of another first-order predicate standing for a formal property of existence, i.e., as a universal extension. ${ }^{33}$ As Lewis himself had intuited; for him, so interpreted, Routley "affirms the existence of all the controversial entities (as we may call them). He does not join us when we dodge questions about some of these alleged entities by denying that they exist." (1990:29). Thus, sticking to the same quantifier as being endowed with the very same meaning makes both Routley and his Quine-inspired adversary to be allists, in Lewis' sense; namely, to be people quantifying on everything, i.e., everything that formally exists. Yet it does not make them the same kind of allists. For so interpreted, Routley accepts in the overall ontological domain, i.e., the domain of what formally exists, what the Quine-inspired philosopher instead rejects, i.e., some at least of the controversial entities (impossibilia above all). ${ }^{34}$ Put alternatively, the disagreement is a disagreement that affects the truth-value of the relevant quantified sentences, as relativists on this matter would say. ${ }^{35}$

To see this point, to begin with, let me see how to interpret, first, the disagreement between Meinong and some of the Quine-inspired philosophers, namely, those among the Quine-inspired philosophers who accept at least some abstracta (just as the mature Quine did), ${ }^{36}$ and second, let me introduce noneists into the picture. In actual fact, appearances notwithstanding, both for Meinong and for those Quine-inspired philosophers there is a first-order predicate of existence whose extension is universal - the predicate applies to all items in the overall ontological domain - thereby standing for a certain first-order not only universal but also formal property of existence, a property that makes no difference to the items that have it. This property has been given different labels: being (Russell 1937), ${ }^{37}$

\footnotetext{
${ }^{33} \mathrm{~A}$ caveat. In what follows, I will talk of different first-order predicates of existence that respectively stand for different first-order properties of existence. One may prefer saying that there is just one first-order predicate of existence that is ambiguous, by meaning different such properties.

${ }^{34}$ In this respect, unlike the Routleyan allist, the Quine-inspired allist does not hold that "any object that the the noneist embraces is a denizen of the allist's ontology" (Woodward 2013:183). In order to better grasp this point, the following story may be useful. Suppose that the existential quantifier ranged over whatever is in a picture; whatever is in the picture constitutes the overall ontological domain. The Routleyan allist and the Quine-inspired allist would agree on the meaning of that quantifier, but would disagree on what is in the picture, or in other words, on the cardinality of the overall ontological domain. The Routleyan allist would hold that there are many more things in the picture than the Quine-inspired allist would acknowledge - say, invisible parts of objects.

${ }^{35}$ Cf. e.g. Recanati (2007). However, it is not a faultless disagreement, for both parties have their own reasons as to why things have to be seen as they claim. Even Quine himself would be ready to accept this way of putting things. For, as he says, the disagreement in question consists in the two parties different sayings as to what there is (1953:15-6), thereby suggesting that such sayings differ in their truth-value.

${ }^{36}$ As it will immediately emerge soon below, I distinguish these Quine-inspired philosophers from those who, like the young Quine, accept just concreta; namely, those kinds of things that are qualified by what I will later call P-existence, i.e., existence as being endowed with causal powers.

${ }^{37}$ Pace the standard noneist interpretation (cf. e.g. Routley 1980:437, Priest 2016:106,251), Russell's
} 
existence in a logical sense (Williamson 2002), being identical with something (Lewis 1990), being an object (Berto 2013:68). As Lewis himself proceeds in the above quotation, Routley "quantifies just as we do; over everything; that is (as we would say) over everything that exists" (1990:29; my italics). Here "exists" means precisely this first-order, formal and universal property.

Yet moreover, in actual fact those Quine-inspired philosophers take this predicate to be coextensional with another first-order predicate of existence that stands for a different firstorder property, a substantive property of existence, a property that makes a difference to the items that have it: an object having this form of existence must have entered the spacetime, or must have been introduced via some sort of mathematical demonstration. Here is where the disagreement with Meinong arises. For Meinong would deny that the first first-order predicate and the second first-order predicate are coextensional, by conceiving the firstorder substantive property the second predicate stands for as being nonuniversal, insofar as only some items within the overall ontological domain have it. This is what Meinong called Sein and that we might rename in his honour $M$-existence. This is a property that both some concreta, i.e., items possibly having spatiotemporal connotations (e.g., Everest and Mont Blanc), and some abstracta, i.e., items necessarily having no spatiotemporal connotations (e.g., the square and the circle), possess, while some other concreta (e.g., the golden mountain) and some other abstracta (e.g, the round square) fail to possess it (where Meinong further labels subsistence (Bestand) the property of $M$-existing while necessarily having no spatiotemporal connotations that just abstract items may possess).

At this point, furthermore, noneists come on stage, by spreading Meinong's disagreement with other Quine-inspired philosophers, those who accept just concreta (as the young Quine did). Noneists may be taken to claim that the first first-order predicate, the predicate that stands for the formal and universal first-order property, is not even coextensional with another first-order predicate that stands for an even more substantive and definitely nonuniversal first-order property of existence, a property that makes a big difference to the items that have it. To quote Routley himself: "existence often makes a substantial difference to an object and to its character; e.g., removal of existence by death or destruction can make the difference between a lively energetic creature and a lifeless object that was (even briefly), before, that creature" (1980:51). This is the property some people have labeled existence in a physical sense (Williamson 2002) and that noneists tend to take, à la Plato, as being endowed with causal powers: P-existence, let us say, which may be further seen as being the same as having spatiotemporal connotations. ${ }^{38}$ Now, noneists ascribe to these other Quine-inspired philosophers the contrary coextensivity claim that for them is erroneous, namely the claim that the first-order predicate that stands for the formal universal property of existence is coextensional with the first-order predicate that stands for

being is not the same as Meinong's Sein, which includes both things existing spatiotemporally and things existing nonspatiotemporally (subsisting). For one thing, chimeras have being for Russell, Nichtsein for Meinong.

${ }^{38}$ Cf. Castañeda (1989), Priest (2016:xxvii-xxviii), Berto (2013:61-5). 
the more substantive property of existence, P-existence. ${ }^{39}$ See again Lewis: "If 'existence' is what he thinks it is a distinction among the items we are committed to-then we dispense with existence." (1990:30). ${ }^{40}$

As a result of this (admittedly complex) situation, the disagreement between such parties - the different sorts of Quine-inspired philosophers on the one side, Meinong and the noneists on the other side - manifests itself in the different evaluation of certain quantified sentences where the quantifier actually keeps the same meaning. To be sure, noneists also believe that the first-order predicate of existence that occurs in such sentences is not the same as the predicate that both for the first group of Quine-inspired philosophers and Meinong those sentences mobilize, since for them that predicate does not stand for Sein, as both those Quine-inspired philosophers and Meinong instead hold, but for the more substantive property of existence, P-existence. Thus for noneists, a small difference of meaning in those sentences still arises as to the first-order predicate occurring there. Take e.g.:

(8) There are no nonexistent objects.

(8) is (trivially) true for those Quine-inspired philosophers, yet false both for Meinong and for noneists. For those Quine-inspired philosophers, (8) is true. For they take the substantive property that the second first-order predicate of existence figuring in it stands for, Sein, as universal and therefore coextensive with the first-order formal property of existence the first first-order predicate of existence stands for, being an object, thereby fixing the scope of the overall ontological domain over which the quantifier figuring in (8) ranges. ${ }^{41}$

\footnotetext{
${ }^{39}$ So interpreted, these Quine-inspired philosophers are different from the previous Quine-inspired philosophers who actually endorse the previous coextensivity claim that for Meinong is erroneous as well; namely, the claim that the first-order predicate that stands for the formal universal property of existence is coextensional with the second first-order predicate of existence that stands for the merely substantive property of existence, Sein. Thus, it is not thoroughly exact to say "where the noneist says that something is an object, the Platonist [i.e., the fan of abstracta] says it exists, using the word less restrictively than the noneist" (Hale 2007:109). For one should rather say that where the noneist says that something is an object, the Platonist says the same, plus that it also exists, using (erroneously, for the noneist) the word less restrictively than the noneist.

${ }^{40}$ One might suspect that this proliferation of substantive first-order properties amounts to postulating ways of being that specify the formal first-order property of having being. In this vein, one may wonder up to what extent the Quine-inspired philosophers I have appealed to here are really Quinean, since Quine notoriously rejected ways of being (1960:242). To be sure, one might immediately reply that the above properties are not ways of being, insofar as the latter amount to second-order properties expressed by restricted existential quantifiers (cf. McDaniel 2009:302-3). Yet this reply is controversial, for one may wonder whether first-order substantive properties come back from the rear door as what induces the restrictions. To my mind, a better reply is that such properties are not exclusive, for one and the same thing (e.g., a concretum) may both P-exist and have Sein, whereas ways of being are (tendentially at least) exclusive (cf. again McDaniel, ib.:312). An even better reply is that such properties are not ways of being for, rather than restricting the scope of the quantifier, they serve to determine the scope of the overall ontological domain on which the unrestricted quantifier ranges.

${ }^{41}$ Mutatis mutandis, the same holds for the second group of Quine-inspired philosophers, insofar as they
} 
Yet for Meinong (8) is false, for he takes that substantive property as nonuniversal, thereby failing to fix the scope of the overall ontological domain over which the quantifier figuring in (8) ranges. As a consequence, Meinong would take (8) as true only if its quantifier were contextually restricted to existents in the sense of the substantive, for him nonuniversal, first-order property of existence, Sein. For noneists, (8) is false as well, insofar as they however hold that the sentence contains another first-order predicate that stands for a more substantive and still nonuniversal property of existence, $P$-existence. In this, they part company both with those Quine-inspired philosophers and with Meinong, for both those Quine-inspired philosophers and Meinong take that the first-order predicate occurring in (8) to stand for the substantive Meinongian property of existence, Sein, that the first take as universal while the second takes as nonuniversal. ${ }^{42}$ As a consequence, noneists would take (8) as true only if its quantifier were contextually restricted to existents in the sense of the more substantive, for them nonuniversal as well, first-order property of existence, P-existence. Conversely,

(9) There are objects that do not exist

is false, if not even contradictory, for those Quine-inspired philosophers. For they take the substantive property that the second first-order predicate of existence figuring in it stands for, Sein, as universal, thereby fixing the scope of the overall ontological domain over which the quantifier figuring in (9) ranges. ${ }^{43}$ Yet for Meinong (9) is true, for he takes that substantive property as nonuniversal, thereby failing to fix the scope of the overall ontological domain over which the quantifier figuring in (9) ranges. For noneists, (9) is true as well, insofar as they hold, unlike both those Quine-inspired philosophers and Meinong, that the sentence contains another first-order predicate as standing for a more substantive and still nonuniversal property of existence, P-existence. Moreover, what allows both Meinong and the noneists to take (8) false and (9) true is the fact that they take the scope of the overall ontological domain over which the quantifier figuring in (8) and (9) ranges to be fixed just by the formal universal property of existence that, as I said before, another first-order predicate of existence stands for: being an object. Indeed for them,

(10) There are objects that are not objects

take the more substantive property that for them the first-order predicate of existence figuring in (8) stands for, P-existence, as universal and therefore coextensive with the first-order formal property of existence another first-order predicate of existence stands for, being an object.

${ }^{42}$ This is what allows a noneist to take modal sentences like "Holmes does not exist, but might have done so" and "Routley existed, but might not have done so" to be true without any need for her to be reformulated. Cf. Priest (2016:152-5,199-204).

${ }^{43}$ Mutatis mutandis, the same holds for the second group of Quine-inspired philosophers, insofar as they take the more substantive property that for them the first-order predicate of existence figuring in (9) stands for, P-existence, as universal.

Australasian Journal of Logic (15:2) 2018 Article no. 2.5 
where that first-order predicate occurs, would be false, if not even contradictory. This is a result of merely assuming the first-order formal universal property that the first-order predicate occurring in (10) stands for, being an object, to fix the scope of the overall ontological domain over which the quantifier figuring in (10) ranges. ${ }^{44}$ Incidentally, the above Quine-inspired philosophers would agree on that evaluation, but as we have seen, they would take (10) to be false, or even contradictory, because they take that formal universal property of existence to be coextensive with the substantive first-order property of existence, Sein.

I can immediately figure out what, also on behalf of Meinong himself, a standard noneist would immediately protest. True enough, she may say, there may be a first-order predicate that stands for a formal universal property, however suitably conceived: being an object, or even being given (a possibility that Meinong himself suggested). ${ }^{45}$ But that property has nothing to do with existence! For the only genuine property of existence is the property that I have previously qualified as the more substantive one, which divides nonexistents (mathematical items and possible worlds included) from existents: P-existence. This is the property that is mirrored by the loaded particular quantifier, i.e., what is the same, the standard noneist would go on saying, as the Quinean existential quantifier (what is expressed by "there exists", if not also by "there is" $)^{46}$, for it is included in its definition that also involves the unloaded particular quantifier ("there exists/is something, $x$, such that $A(x)$ " is "something, $x$, is such that it exists and $A(x)$ ") ${ }^{47}$ This is moreover why existence has, pace Quine, nothing to do with particular quantification, either loaded (existential quantification) or even unloaded.

Yet it seems to me that this protest is not correct. First of all, as I have tried to show, all such first-order properties are involved whenever there is an ontological disagreement: such properties are respectively taken by the participants in that disagreement to be what fixes the scope of the overall ontological domain. ${ }^{48}$ Hence moreover, that disagreement concerns a disagreement as to the scope of ontological commitment, i.e., as to what one has to put within that domain. In this respect, all such properties have to do with existence in a very general sense. Finally, the quantification whose scope is so affected by such

\footnotetext{
${ }^{44}$ Cf. Priest's response (2016:249-50) to a similar sentential case proposed by Kroon (2008): "Some things, including Gandalf and the golden mountain, don't exist in any sense whatever; in reality, they are nothing". Kroon (ib.:206) adds that the sentence may be fictionally true. This may well be the case, but for me it is quite compatible with its being literally false.

${ }^{45}$ Cf. Meinong (1960:108). Yet later (1978) he seems to have admitted that this property has an existential flavor. For the distinction between the formal universal property a certain first-order predicate stands for and existence, cf. Priest, e.g. (2016:245fn.32) - even if he admits that for Quineans at least, what he calls the vacuous predicate "to be identical with something" is a predicate of existence: $i b .: 14$, xxviii,fn.16.)

${ }^{46}$ For Priest, "there is" and "there exists" mean actually the same thing (for a few exceptions, cf. his discussion in 2016: chap.17). On this Routley is more uncertain, by allowing "there is" to be somehow ambiguous between the unloaded and the loaded quantifier - cf. e.g. (1980:28)

${ }^{47}$ Cf. Priest (2016:14).

${ }^{48}$ Another way of putting the disagreement is to say that what for the 'desertic' party simply fixes the overall ontological domain, for the 'overpopulating' party simply restricts it.
} 
properties, i.e., existential quantification, which in this interpretation is the only such quantification there is, has also to do with existence in this general sense. As Quine wished along with a tradition stemmed out of Frege and Russell that however interpreted existence merely as a second-order property, instantiatedness. For whenever it shows that certain status properties ${ }^{49}$ are instantiated, true existential quantification shows what really figures in such a domain. If e.g. (9) is true, it shows that the status property of being a nonexistent object (the complement of Sein, the substantive property of existence) is instantiated, thereby also showing that nonexistent objects figure in the overall ontological domain. ${ }^{50}$ Just as different such sentences to the effect that there are fictional objects, mathematical objects, concrete objects etc. would show, by also showing, if true, that the corresponding categorical properties - being a fictional object, being a mathematical object, being a concrete object, etc. - are instantiated.

As a final moral, therefore, one may say that a noneist reconstructed along the admittedly nonstandard lines is committed to a plurality of different yet interconnected properties of existence that all capture something that has to do with existence in general. These properties are at least two, if not three, first-order properties of existence, a formal and universal property, being an object, and a substantive nonuniversal property, Sein, or even better for a noneists, a more substantive and still nonuniversal property, P-existence, as well as a second-order property expressed by the existential quantifier. ${ }^{51}$ As a syncretist towards existence would say, the contraposition between Quine-inspired philosophers as defenders of existence as a second-order property and noneists as defenders of existence just as a both (very) substantive and nonuniversal first-order property has no longer reason to subsist. ${ }^{52}$

\section{Acknowledgements}

I thank Fred Kroon, as well as an anonymous reviewer for this journal, for their comments on an earlier version of this paper.

\footnotetext{
${ }^{49}$ For this labeling, cf. Priest himself (2016:216).

${ }^{50}$ If we adopt Meinong's stance on the matter; for noneists, (9)'s truth shows that the complement of the more substantive property of existence, i.e., the status property of being an object that has no P-existence, is instantiated.

${ }^{51}$ So construed, one may say that the various existence predicates amount to an expression that, in McDaniel's terms, has a focal meaning, i.e., it is such that "it has several senses, each of which is to be understood in terms of some central meaning" (2009:294).

${ }^{52}$ For more on this see Voltolini (2012).
} 


\section{References}

Berto, F. (2013). Existence As a Real Property. Dordrecht: Springer.

Castañeda, H-N. (1989). Thinking, Language, and Experience. Minneapolis: University of Minnesota Press.

Crane, T. (2001). Elements of Mind. Oxford: Oxford University Press.

Crane, T. (2013). The Objects of Thought. Oxford: Oxford University Press.

Hale, B. (2007). "Into the Abyss". Philosophia Mathematica 15: 94-110.

Kriegel, U. (2011). The Sources of Intentionality. Oxford: Oxford University Press.

Kroon, F. (2008), "Much Ado About Nothing: Priest and the Reinvention of Noneism". Philosophy and Phenomenological Research 76: 199-207.

Lewis, D. (1990). "Noneism or Allism?". Mind 99: 23-31.

McDaniel, K. (2009). "Ways of Being". In D.J. Chalmers, D. Manley and R Wasserman (eds.), Metametaphysics: New Essays on the Foundations of Ontology. Oxford: Oxford University Press, 290-319.

McGinn, C. (2002). Logical Properties. Oxford: Oxford University Press.

Meinong, A. (1960). "On the Theory of Objects". In R. Chisholm (ed.), Realism and the Background of Phenomenology, New York: Free Press, 76-117.

Meinong, A. (1978). "Über Inhalt und Gegenstand", in Kolleghefte und Fragmente. Ergänzungsband zur Gesamtausgabe. Graz: Akademische Druck- und Verlagsanstalt, 145159.

Priest, G. (2016). Towards Non-Being: the Logic and Metaphysics of Intentionality. Oxford: Oxford University Press.

Quine, W.V.O. (1953). "On What There Is". In From a Logical Point of View, Cambridge MA: Harvard University Press, 1-19.

Quine, W.V.O. (1960). Word and Object. Cambridge MA: MIT Press.

Recanati, F. (2007). Perspectival Thought. Oxford: Oxford University Press.

Routley, R. (1980). Exploring Meinong's Jungle and Beyond. Canberra: Australian National University.

Russell, B. (1905a), "On Denoting". Mind 14: 473-493.

Russell, B. (1905b), "Critical Notice. Untersuchungen zur Gegenstandtheorie und Psychologie hrsg. von A. Meinong". Mind 14: 530-538.

Russell, B. (1937). The Principles of Mathematics. Cambridge: Cambridge University Press.

Australasian Journal of Logic (15:2) 2018 Article no. 2.5 
Sainsbury, M. (2010). "Intentionality without Exotica". In R. Jeshion (ed.), New Essays on Singular Thoughts, Oxford: Oxford University Press, 300-317.

Sainsbury, M. (2017), "Intentional Relations". Argumenta 4: 327-339.

Sainsbury, M., and Tye, M. (2012). Seven Puzzles of Thought and How to Solve Them. Oxford: Oxford University Press.

Smith, A.D. (2002), The Problem of Perception. Cambridge (MA): Harvard University Press.

Thomasson, A.L. (1999). Fiction and Metaphysics. Cambridge: Cambridge University Press.

Voltolini, A. (2012). "All the Existences That There Are" Desputatio 32: 361-383.

Williamson, T. (2002). "Necessary Existents". In A. O' Hear (ed.), Logic, Thought and Language, Cambridge: Cambridge University Press, 233-251.

Woodward, R. (2013). "Towards Being". Philosophy and Phenomenological Research 86: 183-193. 